\title{
Los insectos y el biodeterioro del Patrimonio Histórico Cultural
}

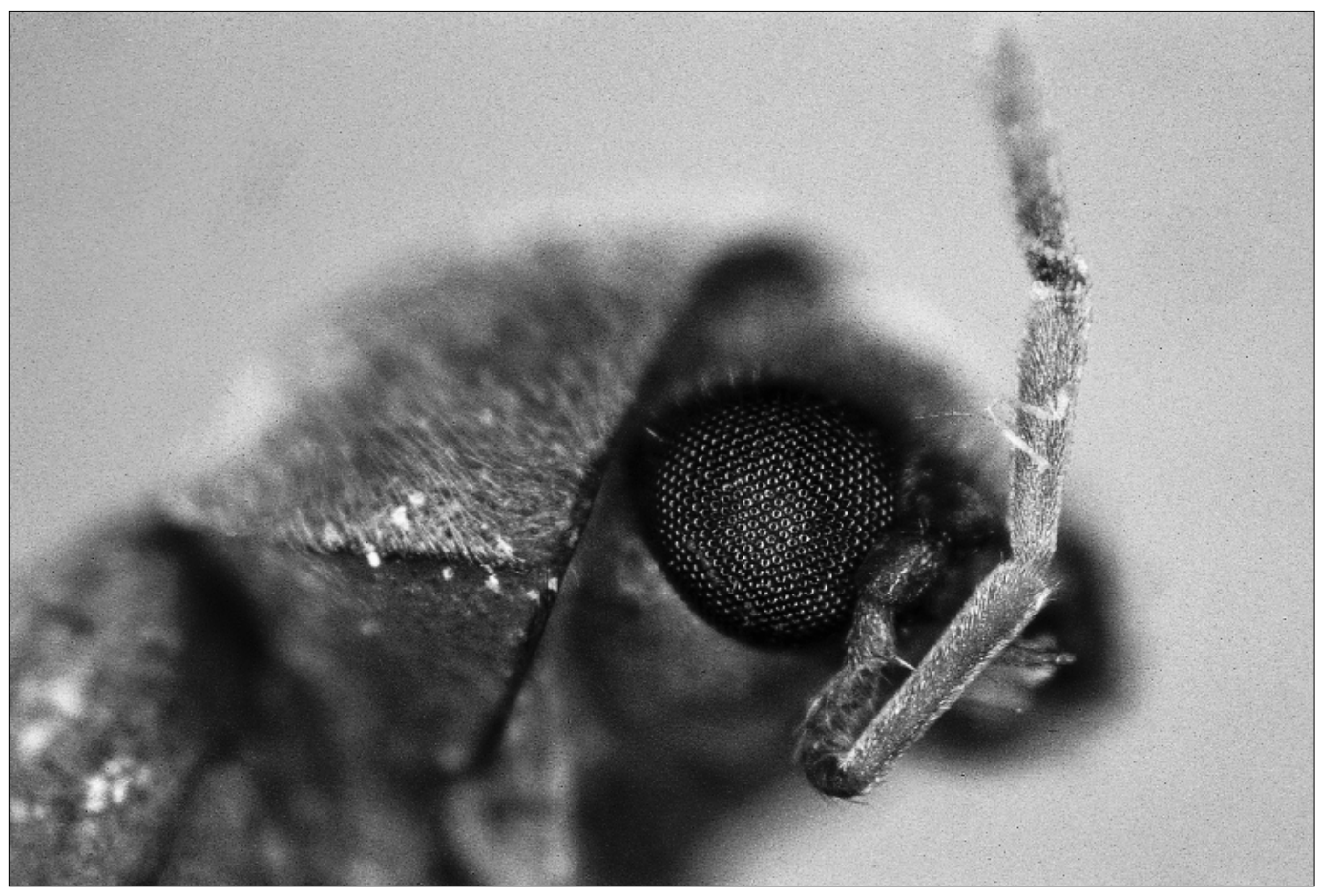

José Luis Yela

Unidad de Ecología Evolutiva. Estación Biológica de Doñana,

CSIC.

\section{Marta Sameño}

Departamento de Análisis. Instituto Andaluz de Patrimonio Histórico

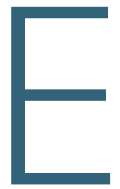

n anteriores números del Boletín han aparecido ya artículos sobre la naturaleza del proceso de biodeterioro' y sobre ciertos organismos que lo producen ${ }^{2}$. Aquí vamos a tratar de dar algunas ideas generales sobre aquellos insectos que causan daños sobre materiales histórico-culturales que pueden encontrarse en el área geográfica ibérica, y más especialmente en Andalucía.

\section{Los insectos: definición y diversidad}

La mayoría de las personas tenemos una idea intuitiva de lo que es un insecto: un animal generalmente pequeño, cubierto con un exoesqueleto quitinoso formado por placas articuladas, con tres pares de patas $y$, por lo general, con dos pares de alas (que pueden faltar o estar reducidas) ${ }^{3,4}$. Sin embargo, esta definición atañe solamente a una de las fases del ciclo vital de los insectos: la de adulto. De las otras tres fases (huevo, ninfa y náyade en los insectos heterometábolos o exopterigotas; huevo, larva y pupa, en los holometábolos o endopterigotas), la de ninfa o larva es con gran diferencia la que más nos interesa aquí, puesto que ninfas y larvas de bastantes especies son las causantes de daños de importancia sobre objetos artísticos o culturales. Las ninfas son, para enten- 


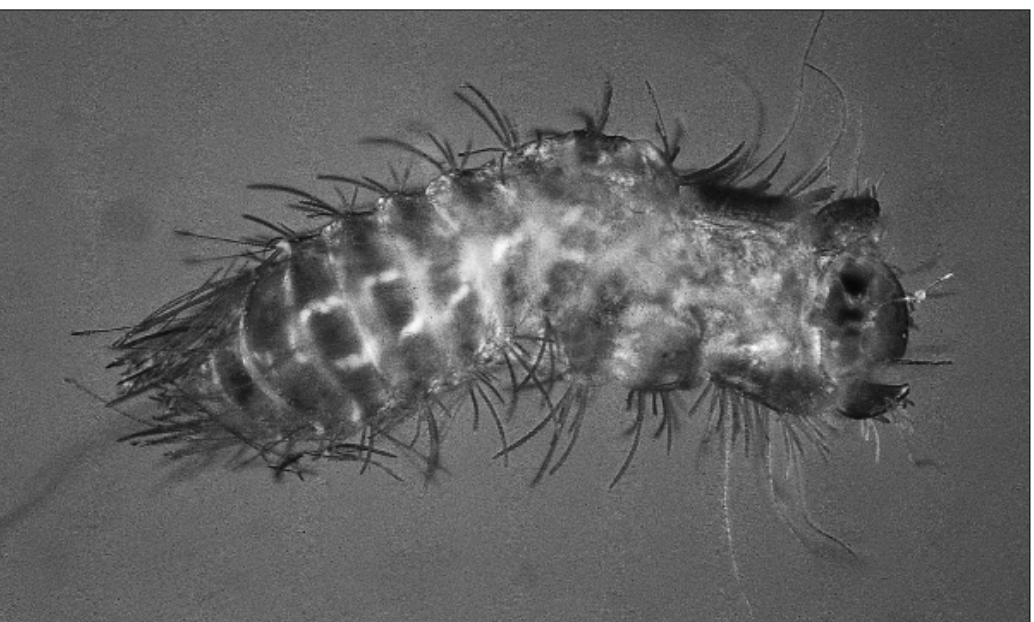

son el grupo de organismos vivientes más diverso, por encima de otros como los hongos o las bacterias. Representan no menos del $60 \%$ de todas las especies vivientes descritas hasta el momento5,6. Se han descrito ya entre $750.000^{7,8}$ y I millón ${ }^{5,9}$ de especies de insectos en todo el mundo, pero estimaciones recientes sitúan el número de especies que probablemente exista entre I millón y medio y 10 millones $10,11,12$. Se supone que en el área iberobalear debe haber alrededor de 50.000 especies ${ }^{13,14}$. El éxito evolutivo de los insectos ha sido extraordinario, habiéndose adaptado prácticamente a todos los ambientes no marinos 3 15. No es, pues, extraño, que algunos de ellos se hayan especializado en utilizar recursos producidos o manipulados por la especie humana. La mayoría de ellos siguen manteniendo poblaciones silvestres, si bien muestran un mayor o menor grado de abandono de la vida silvestre para asociarse a la actividad humana; unos pocos la han abandonado totalmente, y se han vuelto dependientes por completo de nuestra propia especie. Son notables ejemplos de vinculación a las condiciones humanas los insectos productores de enfermedades, de plagas agrícolas y forestales, y aquellos otros que habitan o atacan a viviendas y enseres de todo tipo. Entre estos últimos están los causantes de deterioro en obras de arte y bienes culturales.

\section{Actividades de los insectos como causa de biodeterioro}

Cuatro son las funciones principales en que se ocupan los insectos a lo largo de su ciclo vital: alimentación, refugio, reproducción y dispersión ${ }^{3,16}$. Es al satisfacer alguna de ellas cuando pueden producir los tipos fundamentales de daño. Sin duda, las actividades relacionadas con la alimentación son las principales causantes de biodeterioro, que puede ser producido mecánicamente (al arrancar el animal con las mandíbulas parte del objeto atacado) o químicamente (por efecto de sustancias presentes tanto en la saliva y otras secreciones bucales como en los excrementos). La búsqueda de refugio tiene un papel algo menor en el biodeterioro $y$, junto a la actividad reproductora, produce alteraciones de naturaleza fundamentalmente mecánica (al horadar cavidades o remodelar materiales donde protegerse, o al construir "nidos" donde llevar a cabo la cópula o la puesta). Por último, si bien la dispersión como tal no conduce a biodeterioro, es interesante señalar el papel que el traslado humano de materiales puede tener como vector de la dispersión pasiva de insectos. Bastantes de los insectos reconocidos como dañinos han ampliado mucho sus áreas de distribución debido a que han sido traslados, junto al material en el que se cobijan, de la zona que habitaban originalmente a otras donde no estaban presentes, y en las cuales han podido sobrevivir ${ }^{15,17,18}$. Así, algunas de las especies que se van a mencionar líneas más abajo proceden de Norteamérica o Centroeuropa, y se han aclimatado a las condiciones reinantes en nuestro país (en algunos casos, por hallarse los materiales que deterioran dentro de habitáculos humanos, lo que implica que las condiciones ambientales no son severas).

\section{Materiales atacados e impacto producido}

Como se ha señalado, las actividades alimentarias de los insectos son de importancia máxima en relación al biodeterioro, ya sea éste producido por ninfas o larvas o por adultos. Se pueden proponer diferentes clasificaciones de los tipos de material atacado por los insectos y de los daños infligidos ${ }^{19,20,21}$, una de las cuales es la siguiente:

\section{A. Material de origen vegetal:}

I. Madera: vigas, marcos, mobiliario, techos, suelos y tallas son atacados básicamente por escarabajos (Coleoptera), de entre los cuales el "gusano de la madera" o "carcoma común de los muebles" Anobium punctatum (Anobiidae) es con gran diferencia el "insecto estrella"19. Existen otras especies de coleópteros (relacionadas más abajo) que, bajo las condiciones ambientales que se dan en Andalucía, pueden causar desperfectos notables, en especial Lyctus brunneus, L. linearis (Lyctidae) e Hylotrupes bajulus (Cerambycidae). Sin embargo, es A. punctatum la que ocasiona la mayor parte de los daños al excavar sus larvas galerías en la madera, pudiendo reducir techumbres, muebles y suelos enteros a serrín en relativamente poco tiempo 15,19,22. Entre los 
restos de serrín se observan sus excrementos que tienen una forma característica. La mayoría del resto de los insectos de importancia en el deterioro de maderas sólo tiene importancia local; entre ellos podemos citar las termitas (Isoptera), que construyen sus nidos en la madera vieja, pudiendo llegar en algunos casos a producir un daño irreversible en vigas de madera; ciertas cucarachas (Dictyoptera), cuyos daños suelen ser superficiales y debidos al efecto de la masticación de madera humedecida; y algunas avispas (Hymenoptera), que arrancan trozos de madera para hacer una pasta junto a su saliva con la cual fabricar el papel de sus nidos (pero cuyos daños hay que catalogar también de escasos).

2. Papel y otros derivados de la celulosa (herbarios, pergaminos, etc.): pueden raerlos especies de varios órdenes de insectos, aunque los mayores daños son producidos por el "piojo de los libros" Liposcelis corrodens (Psocoptera), los "pececillos de plata" Lepisma saccharina y Thermobia domestica (Thysanura), algunos escarabajos anóbidos y líctidos (véase más abajo), el derméstido Attagenus piceus (Coleoptera) y algunos termes (véase más abajo).

3. Barnices y resinas: pueden ser desgastados por la acción masticadora de ciertos coleópteros derméstidos, sobre todo del género Dermestes, al tratarse de sustancias grasas.

4. Alfombras y telas de origen vegetal (algodón, lino): excepto por lo que se refiere a derméstidos del género Attagenus (que son frecuentes en alfombras), son escasos los daños producidos por insectos sobre tejidos de origen vegetal, aunque se pueden observar en ocasiones mordeduras de tisanuros, de ciertos escarabajos (otros derméstidos) y de cucarachas (blatélidos).

\section{B. Material de origen animal:}

5. Cuero, pelo, piel o plumas: El principal enemigo de estos materiales son los escarabajos derméstidos, que pueden llegar a hacer desaparecer el material original y dejarlo reducido a un fino polvo ocráceo (compuesto por sus excrementos).

6. Tejidos y telas de origen animal: en ocasiones pueden ser atacados por la mordedura de escarabajos derméstidos y cucarachas, pero los mayores daños los producen las "polillas de la ropa" (Lepidoptera), que en general producen agujeros de entre dos y tres milímetros y varios centímetros de diámetro.

Como se ve, los daños causados por insectos afectan fundamentalmente a materiales orgánicos. Los daños en materiales inorgánicos (de tipo pétreo) son relativamente raros (aunque en algún caso pueden ser graves). Los ejemplos más reseñables se refieren todos ellos a himenópteros, y son: I) la construcción de nidos de barro (cámaras de cría), de naturaleza muy compacta, llevada a cabo por ciertas avispas (esfécidos y véspidos), que pueden llegar a cubrir superficies im- portantes en muros, paredes o esculturas; 2) el aprovechamiento de grietas y la subsiguiente excavación de galerías de refugio y reproductoras llevado a cabo por ciertas avispas y abejas cortadoras de hojas (véspidos, andrénidos, antofóridos y halíctidos); y 3 ) la excavación de habitáculos en la base de edificaciones efectuada ocasionalmente por algunas hormigas (formícidos). Los restantes tipos de deterioro sobre materiales inorgánicos están producidos exclusivamente como consecuencia indirecta de la presencia de insectos (por acúmulo transitorio de ejemplares que pueden atraer a presas como ratones y murciélagos).

Cabe resaltar la aparente paradoja que supone hallar en ocasiones insectos que, en principio, "no deberían" estar sobre determinados sustratos. Así, sobre una obra de arte en concreto ("Colección de planchas para imprimir naipes"), cuyo material constitutivo es la madera, se han encontrado restos de exuvias de larvas de coleópteros derméstidos (Anthrenus sp), los cuales no atacan la madera, a no ser que esté impregnada de materias grasas ${ }^{19}$. Dichas exuvias sólo han aparecido sobre algunas de las planchas. Un examen detallado ha permitido constatar que algunas de ellas habían sido tratadas con una sustancia parafinada (de naturaleza grasa), y es precisamente allí donde aparecen las exuvias. Las larvas de derméstidos se estarían alimentando de la capa de parafina y, eventualmente, de la madera en contacto con ella; pero no de la madera sin tratar.

Otro caso en el que se han encontrado exuvias de larvas de derméstidos ha sido en una pintura sobre tela. Al poseer cola de orígen animal, la obra ha sufrido un ataque por parte de estos insectos.

Como se ha visto, el grado de vinculación de los insectos dañinos con el material que atacan es variable. Algunas especies pueden considerarse constantes, en el sentido de que su presencia delata un tipo de daño concreto que varía poco cualitativamente aunque mucho cuantitativamente, y que apenas se encuentran en otro hábitat que el proporcionado por el material artístico (por ejemplo, la carcoma de los muebles); otras, sin embargo, son más o menos accidentales; se encuentran asociadas a otros ambientes, $y$ en general producen daños de poca importancia (como ciertas cucarachas).

\section{Principales plagas de insectos causantes de biodeterioro en España}

Para un reconocimiento fiable de las distintas especies existen buenas figuras en diferentes obras; se recomienda al lector interesado recurrir a Chinery 15 (adultos), Bletchly 19 (adultos y larvas de xilófagos), Pinni$\operatorname{ger}^{20}$ (algunos adultos), Bernis 22 (algunos adultos $y$ larvas xilófagos) y, sobre todo, Kingsolver ${ }^{23}$ (adultos y larvas y datos biológicos).

\section{Orden Thysanura}

Familia Lepismatidae

- Lepisma saccharina Linnaeus, "pececillo de plata"15,23. Este detritívoro no desdeña derivados de la celulo- 
sa (papel, textiles vegetales, cartón), así como las colas y adhesivos que unen las hojas de libros y documentos. Ninfas y adultos producen un raspado irregular sobre la superficie. Su color es gris plateado, y su tamaño oscila entre 9 y $12^{\prime} 5 \mathrm{~mm}$. Los huevos tardan entre 19 y 43 días en eclosionar; el periodo ninfal dura entre 3 y 4 meses; y los adultos viven entre 2 y 3 años y medio. La especie es cosmopolita y muy abundante en lugares umbrosos, recogidos y húmedos.

- Thermobia domestica (Packard), "insecto del fuego" o "termobia de las tahonas"15,23. Las preferencias, daños y biología son análogos a los de la especie anterior, si bien ésta es más termófila. Su color es también gris plateado, pero con un dibujo oscuro en la superficie dorsal.

\section{Orden Dictyoptera}

\section{Familia Blattidae}

- Blatella germanica (Linnaeus), "cucaracha rubia o alemana"15,23. La ninfa y el adulto atacan, entre muchos otros materiales, sustancias amiláceas (colas, pegamentos), cuero y, en ocasiones, madera humedecida o en putrefacción. Los daños se limitan generalmente a raspaduras y mordeduras, que a veces pueden ser de importancia. El adulto es pequeño ( I I a $14 \mathrm{~mm}$ ). El color de ninfas y adultos es ocre pálido, con dos bandas oscuras en el pronoto. A veces su presencia queda de manifiesto por la aparición de las ootecas (de unos $7 \mathrm{~mm}$ ). El ciclo vital dura entre 55 y 68 días, y la hembra puede vivir hasta 200 días. Es cosmopolita y bastante abundante.

- Blatta orientalis (Linnaeus), "cucaracha negra o común"15,20,23. Ninfas y adultos tienen análogas costumbres, y producen similares daños, a los de la especie anterior. El adulto es de tamaño mediano $(26 \mathrm{~mm})$. Color de ninfas y adultos negruzco. La presencia de ootecas $(7 \mathrm{~mm})$ evidencia la de la especie. Duración del ciclo vital: entre 300 y 800 días; la hembra adulta puede vivir hasta casi un año. Cosmopolita y muy abundante, aunque en muchas localidades ha sido desplazada (e includo eliminada) por la siguiente especie.

- Periplaneta americana (Linnaeus), "cucaracha americana"15,20,23. Biología y daños como en las dos especies precedentes. El adulto es de tamaño grande (29 a $40 \mathrm{~mm}$ ). Color de ninfas y adultos pardo avellana. Ootecas de unos $9 \mathrm{~mm}$. Duración del ciclo vital: entre 258 y 616 días; la hembra adulta puede vivir alrededor de un año. Cosmopolita y muy abundante en Andalucía (sobre todo en localidades de invierno suave).

\section{Orden Isoptera}

\section{Familia Kalotermitidae}

- Kalotermes flavicollis (Fabricius), "termita amari"la"15,23. Como todos los termes, los adultos de esta especie se organizan en castas, de las cuales las obreras son el estado que produce los daños. Al igual que otras especies, ésta es xilófaga, degradando la madera seca gracias a la acción de microorganismos simbiontes presentes en su tracto digestivo. Ataca materiales que contengan celulosa (maderas de todo tipo, sobre todo vigas y muebles, también a veces papel o libros). Normalmente no accede al suelo, por lo que es corriente encontrar nidos aislados en muebles, estanterías, etc. Excava galerías; se detecta, sobre todo, por la presencia de un polvo fino (restos de madera y serrín) y por los excrementos, cilíndricos. Tamaño de las obreras: alrededor de $5 \mathrm{~mm}$. Su color es amarillento. Habita en los países ribereños del Mediterráneo y es ocasionalmente abundante, aunque las colonias no son usualmente muy numerosas.

\section{Familia Rhinotermitidae}

- Reticulitermes lucifugus (Rossi)15,22,23. Necesita una humedad alta (mayor del $50 \%$ ). Es una especie fundamentalmente forestal, asociada secundariamente a objetos de madera procesada. Produce galerías irregulares con cámaras de gran tamaño; en su interior deja aglomeraciones de celulosa poco resistentes. Cuando erosiona libros ataca en masa abriendo grandes cavidades. Esta especie y la siguiente son propias del suelo. El color de las obreras es amarillento; su tamaño es de unos 5'5 mm. Es cosmopolita, desplazándose más que la especie anterior y siendo sus colonias más numerosas. Puede ser abundante.

- Cryptotermes brevis (Johnson) 15,22,23. Ataca maderas secas (sus necesidades de humedad son inferiores al $15 \%$ ). Produce galerías irregulares en las que no deja celulosa procesada y aglomerada; habita siempre en partes subterráneas de vigas de madera, a las que erosiona rápidamente y puede destruir completamente. También puede excavar galerías finas individuales en libros. Las obreras, de unos $6 \mathrm{~mm}$ de tamaño, son amarillentas. Es una especie introducida de Norteamérica, muy rara en la Península lbérica.

\section{Orden Psocoptera}

\section{Familia Liposcelidae}

- Liposcelis corrodens Heymons, "piojo de los libros"23. El papel (libros, documentos) es atacado por ninfas y adultos; en él dejan pequeños agujeros y galerías superficiales de tipo irregular. También contribuyen a dispersar hongos y algas dañinos para los derivados celulósicos, acción que puede ser en definitiva más perjudicial que el propio daño mecánico. Su color es blanco grisáceo, y su tamaño minúsculo (I a $2 \mathrm{~mm}$ ). La fase de huevo dura entre 6 y 9 días y la de ninfa entre 24 y 130 días. El adulto vive alrededor de 20 días, y puede haber de 2 a 8 generaciones al año. Parece ser que la especie es partenogenética. Es cosmopolita y en ocasiones abundante. Es posible que exista más de una especie con capacidad para vivir en asociación con el papel.

\section{Orden Coleoptera}

\section{Familia Lucanidae}

- Dorcus parallelepipedus (Linnaeus), "ciervo volante menor"15,19. Especie xilófaga, la larva ataca tocones de árboles silvestres. No daña madera procesada, pero en ocasiones ésta puede mostrar las galerías hechas antes del procesamiento (que son grandes, de $\mathrm{I} \mathrm{cm}$ de diámetro aproximadamente). Es una especie europea meridional, relativamente abundante. 


\section{Familia Buprestidae}

- Las larvas de Buprestis aurulenta (Linnaeus) ${ }^{15,19}$ y Eurythyrea austriaca (Linnaeus) ${ }^{15,19}$ pueden aparecer en objetos de madera, puesto que aunque son especies silvestres, sus ciclos de vida son muy largos (varios años, en ocasiones hasta 30) y las larvas pueden sobrevivir al procesado de la madera. Los adultos, de entre I y $2 \mathrm{~cm}$, tienen brillos metálicos, y las larvas, blanquecinas y gruesas (hasta $2^{\prime} 5 \mathrm{~cm}$ de longitud), excavan galerías de unos 0'7 a 0'9 mm de diámetro. La primera especie es americana (fue importada con la madera), la segunda es europea. Son muy raras en la Península Ibérica.

\section{Familia Dermestidae}

- Dermestes ater De Geer, "escarabajo del tocino negro"23. Ataca preferentemente materiales de origen animal, como huesos, nidos, lana, cuero, etc., pero a veces también maderas y corchos grasos, donde la larva excava cámaras en las cuales pupa. La presencia de todos los derméstidos se pone de manifiesto al hallarse las exuvias (o mudas) de las larvas en el material atacado. El adulto tiene forma elíptica, mide entre 7 y $9 \mathrm{~mm}$, y su color es pardo muy oscuro o negruzco, sin dibujos. La larva es parda amarillenta, con una estría dorsal estrecha, cilíndrica pero ligeramente aplanada (hasta $14 \mathrm{~mm}$ de longitud). Su presencia puede indicar la de restos de pájaros o roedores, a los que frecuentemente se asocia. Huevo: 3 a 4 días; larva: 6 a 9 semanas; pupa: 8 a 9 días; el adulto vive de 2 a 3 meses. Es cosmopolita y abundante.

- Dermestes maculatus De Geer, "escarabajo de las despensas"15,20,23. Ataca los mismos materiales que el anterior, con daños análogos. El adulto es elipsoidal, y se distingue del anterior por su mayor longitud ( 9 a $10 \mathrm{~mm}$ ) y por su color negro sin dibujos pero con una banda marginal de pelo blanco en el pronoto. Además, los élitros poseen una espina terminal y central cada uno. La larva es negra con una estría dorsal ancha, también cilíndrica (hasta $12 \mathrm{~mm}$ de longitud). También suele asociarse con pájaros y roedores. Huevo: 2 a 4 días; larva: 35 a 238 días; pupa: 5 a 30 días; el adulto vive hasta 3 meses. Cosmopolita y muy abundante.

- Dermestes lardarius Linnaeus, "escarabajo del tocino"15,20,23. La larva se alimenta de materiales de origen animal, como pelo, cuernas, huesos, cuero, plumas, nidificaciones, etc., donde construye cámaras pupales. Puede atacar maderas y corchos engrasados. Adulto alargado (7 a $9 \mathrm{~mm}$ ), de color negro con una ancha banda gris en la base de los élitros, en la que se aprecian seis puntos negros (tres en cada élitro). La larva es amarillento-pardusca, con una fina banda entrecortada dorsal sobre el abdomen; es alargada (de hasta $12 \mathrm{~mm}$ de longitud). Puede asociarse con pájaros y roedores. Huevo: 2 a 12 días; larva: 15 a 80 días; pupa: 8 a 15 días; el adulto vive hasta un año y medio. Cosmopolita y muy abundante.

- Anthrenus scrophulariae (Linnaeus) ${ }^{23}$. Alimentación y daños de la larva análogos a los de las especies precedentes. Adulto casi circular (2'2 a 3'5 mm), de color negro con manchas blancas y una ancha banda anaranjada separando ambos élitros. Larva parda oscura, con pinceles de sedas negras (2'5 a 3'5 mm).
El adulto es florícola. Huevo: 13 a 20 días; larva: 60 a 80 días; pupa: 13 a 15 días; el adulto vive hasta un mes. Cosmopolita y abundante.

- Anthrenus flavipes Le Conte23. Alimentación, daños y biología como la especie anterior. Adulto casi circular (2'0 a 3'5 mm), moteado de manchas negras, blancas y amarillas. Larva parda amarillenta, con pinceles de sedas negras (de hasta $5 \mathrm{~mm}$ de longitud). Huevo: 15 a 18 días; larva: 112 a 384 días; pupa: 14 a 19 días; el adulto vive de 32 a 200 días. Cosmopolita y abundante.

- Anthrenus verbasci Linnaeus ${ }^{23}$. Alimentación, daños y biología como en las dos especies anteriores. Adulto casi circular (2 a $3 \mathrm{~mm}$ ), moteado irregularmente de manchas negras, blancas y amarillas. Larva negra y amarilla, con pinceles de sedas negras (4 a $5 \mathrm{~mm}$ ). Huevo: 17 a 18 días; larva: 222 a 322 días; pupa: 10 a 13 días; el adulto vive de 8 a 39 días. Cosmopolita y abundante.

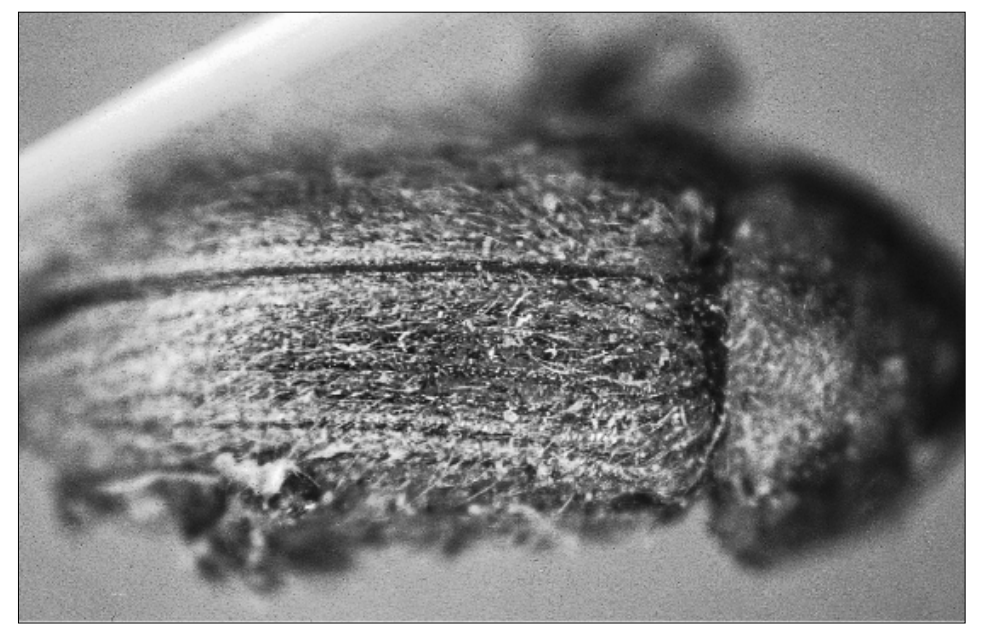

- Thylodrias contractus Motschulsky23. La larva se alimenta, entre otros productos, de tejidos animales como seda y lana, que roe superficialmente. Macho adulto alargado (2 a $3 \mathrm{~mm}$ ), blanco amarillento. Hembra adulta áptera, del mismo tamaño y color. Larva parda, en forma de C, con pinceles de sedas pardas ( $3 \mathrm{~mm}$ ). Huevo: 23 a 30 días; larva: 242 a 338 días; pupa: 7 a 14 días; el adulto vive de 9 a 50 días. Cosmopolita, pero muy raro en nuestras latitudes.

- Trogoderma spp ${ }^{15,23}$. Las larvas de varias especies de este género se alimentan, entre otros productos, de cueros, pieles y otros materiales animales almacenados, que roen superficialmente y en los que excavan galerías. Los adultos son subelípticos, algo alargados, de entre 2 y $4 \mathrm{~mm}$. Las larvas son cilíndricas, amarillas, con pinceles de sedas pardas cortas y diseminadas; su tamaño oscila entre I y $5 \mathrm{~mm}$. Las larvas viven mucho tiempo, entre 5 meses y cuatro años y medio; los adultos tienen vida corta ( 10 a 32 días). Casi todas las especies son cosmopolitas y no raras.

- Attagenus unicolor (Brahm) ${ }^{23}$. Las larvas atacan materiales de origen animal, entre otros lana, seda, cuero, piel, plumas, etc. donde roen superficialmente y excavan galerías. Adultos rechonchos, algo alargados, de entre 3 y $5 \mathrm{~mm}$. Las larvas son alargadas, algo curvadas, pardas o pardo-amarillentas, con se- 
das diseminadas (longitud hasta $8 \mathrm{~mm}$ ). Huevo: 10 a 15 días; larva: 258 a 639 días; pupa: 8 a I 4 días; adulto: 14 a 43 días. Cosmopolita y ocasionalmente abundante.

- Attagenus piceus (Linnaeus), "carcoma de las alfombras"24. La larva se encuentra sobre materias celulósicas (sobre todo libros, papeles diversos, cartones y alfombras), aunque también sobre material de origen animal. Produce erosión superficial y galerías algo más profundas, y puede ser abundante en ocasiones. Es cosmopolita, y su biología y morfología son pareciodos a los de la especie anterior.

\section{Familia Anobiidae}

- Lasioderma serricorne (Fabricius), "cascarudo cigarrero" o "escarabajo del tabaco"15, 19,20,22,23,24,25. Las larvas (causantes del daño) son frecuentes asociadas a plantas conservadas en herbarios, a las que roe superficialmente, aunque en ocasiones puede también encontrarse sobre papel u otros derivados de la celulosa (madera) y sobre artículos de seda. El adulto es pardo rojizo, mide de $2^{\prime} 5$ a $3 \mathrm{~mm}$ y carece de surcos en los élitros. La larva es blanca, con forma de $\mathrm{C}$, y mide unos $3 \mathrm{~mm}$. Es una especie cosmopolita y común, que se detecta por los orificios de salida de los adultos y el fino polvo (serrín y excrementos) alrededor de los objetos atacados. El huevo vive entre 6 y 8 días, el periodo larvario oscila entre 30 y 60 días, el pupal entre 14 y 21 días y los adultos pueden sobrevivir hasta 26 días.

- Stegobium paniceum (Linnaeus), "escarabajo o carcoma del pan"15,19,20,23,24,25. Las larvas producen galerías superficiales e internas y orificios de I a I' $5 \mathrm{~mm}$ de diámetro en materiales celulósicos como productos amiláceos, libros, documentos, herbarios, corcho, cuero, etc. El adulto es algo más oscuro que el de la especie precedente (2'2 a $\left.3^{\prime} 7 \mathrm{~mm}\right)$, y tiene surcos longitudinales en los élitros. La larva es blanquecina y en forma de C, y mide sobre $4 \mathrm{~mm}$. Es cosmopolita y en ocasiones es muy abundante. Huevo: 7 a 12 días; larva: 35 a 50 días; pupa: 8 a 20 días; el adulto vive entre 13 y 85 días.

- Anobium punctatum (De Geer) 15,19,20,22,24,25. Es xilófago y muy frecuente. La mayoría de los ataques a maderas en Andalucía (en condiciones no silvestres) se deben a esta especie. También ataca otros materiales celulósicos como libros, pergaminos o fajos de documentos, y más raramente textiles de origen vegetal. En la madera produce galerías multiestratificadas y orificios de I a I' $5 \mathrm{~mm}$. Los daños más graves se observan en condiciones de mayor humedad y temperatura reducida (pero siempre por encima de unos $10^{\circ} \mathrm{C}$ ). El adulto mide entre 3 (machos) y 5 '5 mm (hembras); su color es pardo oscuro ligeramente rojizo, y tiene surcos en los élitros. Larva blanca, ligeramente curvada; sus excrementos son elípticos, y quedan dentro de las galerías (al no perforar las larvas la superficie). Huevo: 6 a 12 días; larva: 35 a 60 días; pupa: 8 a 15 días; el adulto vive entre 12 y 55 días. Los adultos dejan sus huevos en cualquier rendija o grieta, por lo que los muebles bien pulimentados y barnizados están relativamente a salvo de sus ataques. Hasta que los adultos no abandonan las galerías la presencia de la plaga no es evidente; por esta causa su potencialidad como productor de daños es máxima.

- Ernobius mollis (Linnaeus)19,25. Es xilófago, donde ataca sobre todo la corteza. Es muy raro en la Península lbérica, y apenas se han registrado ataques. Tamaño pequeño (3'5 a $5 \mathrm{~mm}$ ) y color pardusco.

- Dendrobium denticolle (Creutzer) ${ }^{19,25}$. Los mismos comentarios que para la especie anterior.

- Ptilinus pectinicornis (Linnaeus) 19,25. También xilófago, en la Península Ibérica prácticamente sólo se da en el área cantábrico-pirenáica. Se distingue bien por las antenas plumosas de los machos.

- Xestobium rufovillosum (De Geer), "escarabajo del reloj de la muerte"15,19,20,22,24,25. Xilófago. Es bastante raro en la Península lbérica, de donde sólo se conoce de la franja cantábrico-pirenáica. Produce orificios y galerías semejantes a los de Anobium punctatum, pero algo mayores; el adulto mide unos $8 \mathrm{~mm}$, y los excrementos de las larvas (blancas y en forma de C) son redondeados.

- Micobium castaneum (Linnaeus) 19,24,25. Consume derivados celulósicos, sobre todo papel. En libros y fardos de documentos deja galerías y orificios de I a I '5 mm de diámetro. Es raro en la Península Ibérica, y no se conocen ataques producidos en Andalucía. Existen otras especies de anóbidos xilófagas en la naturaleza, pero que muy raramente se encuentran sobre objetos de madera elaborada.

\section{Familia Ptinidae}

- Gibbium psylloides (Czenpinski), "escarabajo araña"19,23. Las larvas producen galerías superficiales e internas en papel, lana y cuero. Los orificios miden entre I y $2 \mathrm{~mm}$ de diámetro. El adulto es fácimente reconocible por sus largas patas; es pardo oscuro, casi negro ( ' '7 a 3'2 mm). La larva es blanca con la cabeza parda, y tiene forma de C ( 3 a $5 \mathrm{~mm}$ ). Es una especie cosmopolita, pero que en España sólo es ocasionalmente abundante. Huevo: 13 a 20 días; larva: 29 a 35 días; pupa: 15 a 18 días; el adulto vive entre 30 y 40 semanas.

\section{Familia Bostrychidae}

- Existe una serie de especies silvestres, todas ellas granívoras y más o menos xilófagas, que en muy raras ocasiones pueden aparecer sobre maderas procesadas. Entre ellas cabe mencionar ${ }^{5,19}$ Bostrychus capucinus (Linnaeus), Rhizopertha dominica (Latreille), Dinoderus minutus (Fabricius), Heterobostrychus brunneus (Murray) y Bostrychopsis parallela (De Geer), cuyo tamaño oscila entre 8 y $17 \mathrm{~mm}$ en estadio larvario y entre 6 y $14 \mathrm{~mm}$ en estado adulto, y cuyo color es en general pardo o rojizo oscuro (excepto B. capucinus, cuyos élitros son de un rojo vivo).

\section{Familia Lyctidae}

- Varias especies de Lyctus 15,19,22,24, a las que se conoce genéricamente como "escarabajos del polvo de la madera", "carcomas" o "polillas del parquet", se pueden encontrar con relativa frecuencia horadando la madera, donde suelen dejar orificios y galerías de alrededor de $1 \mathrm{~mm}$ de diámetro. Las más abundantes son Lyctus linearis (Goeze) y Lyctus brunneus (Stephens), que no son raras también 
atacando objetos de papel o cartón. La plaga se detecta al aparecer un polvo finísimo, difícilmente distinguible del que produce Anobium punctatum. Las larvas son semejantes, pero los adultos presentan un pronoto que no oculta, en norma dorsal, toda la cabeza (en Anobium sí la oculta), y las mazas antenales son bisegmentadas (trisegmentadas en Anobium). Miden entre 2 y $7 \mathrm{~mm}$ de longitud. El resto de las especies aparece casi exclusivamente en la naturaleza, si bien $L$. pubescens (Panzer), L. cavicollis (Le Conte), L. planicollis (Le Conte) (estos dos últimos, importados de Norteamérica) y L. africanus Lesne pueden encontrarse en algunas ocasiones sobre objetos de madera. Otros horadadores de esta familia son Minthea rugicollis (Walker) y Trogoxylon parallelepipedum Melsher, algo más frecuentes que los anteriores, pero tampoco corrientes; el último procede asimismo de Norteamérica.

\section{Familia Cleridae}

- Necrobia rufipes (De Geer), "escarabajo de patas rojas del jamón"15,23. Las larvas son endófagas, y se encuentran sobre todo en carne muerta y jamón, aunque en ocasiones también sobre cuero. Producen galerías más bien superficiales. Pueden dañar tejidos momificados. El adulto es azul oscuro, con brillo metálico y patas rojizas; es peludo, y sus antenas son claviformes (3'5 a $7 \mathrm{~mm}$ ). La larva es blanquecina, con el dorso crema claro y cabeza parda oscura, y tiene forma cilíndrica y alargada ( 9 a $10 \mathrm{~mm}$ ). Es especie cosmopolita, y en España es relativamente abundante. Huevo: 4 a 15 días; larva: 28 a 80 días; pupa: II a 52 días; el adulto vive entre 120 y 140 días.

\section{Familia Lymexylidae}

- Dos especies xilófagas, Hylecoetus dermestoides (Linnaeus) 15,19 y Lymexylon navale (Linnaeus), "broma de las naves"15,19, pueden encontrarse sobre objetos de madera, aunque son raros. Las larvas son blanquecinas y alargadas ( 8 a $18 \mathrm{~mm}$ ), y los adultos muy esbeltos, ligeramente pilosos y con los palpos de los machos muy ramificados (tamaño: 6 a 16 mm). Antiguamente, la segunda especie era muy dañina en las naves de madera; hoy día apenas se registran daños en la madera elaborada.

\section{Familia Cucujidae}

- Oryzaephilus surinamensis (Linnaeus), "carcoma dentada de los granos" o "gorgojo dentado"15,23. Es una especie cosmopolita, a veces abundante en la Península Ibérica. Los daños producidos en material artístico son escasos, pues en general se encuentra asociado a alimentos de origen vegetal. Puede atacar fibras como el lino. Larvas y adultos (ambos son dañinos) producen galerías irregulares, en general superficiales. El adulto es pardo oscuro (2'5 a 3'5 mm), y tiene surcos longitudinales en los élitros; los bordes del tórax son dentados. La larva es cilíndrica, alargada y blanquecina (4 a 4'5 mm). Es cosmopolita y en ocasiones es muy abundante. Huevo: 3 a 5 días; larva: 14 a 50 días; pupa: 7 a 27 días; el adulto vive entre 5 días y 3 años.

\section{Familia Tenebrionidae}

- Tribolium confusum Jaquelin du Va|23. Las larvas producen daños superficiales en herbarios, pero sólo raramente. El adulto es pardo oscuro rojizo (2'6 a $4^{\prime} 4 \mathrm{~mm}$ ). La larva es blancuzca, con un par de "cuernos" anales pardos, así como las mandíbulas; cuerpo cilíndrico y alargado (6 a $7 \mathrm{~mm}$ ). Es una especie cosmopolita y relativamente abundante. Huevo: 6 a 9 días; larva: 16 a 100 días; pupa: 6 a 8 días; el adulto vive hasta 8 meses.

\section{Familia Oedemeridae ${ }^{15,19}$}

- Las larvas de algunas especies de esta familia son barrenadoras de la madera, si bien en condiciones naturales. Alguna vez se ha registrado algún ataque a maderas elaboradas, pero de escasa importancia. Los adultos son florícolas, y el grupo abunda más en latitudes bajas europeas.

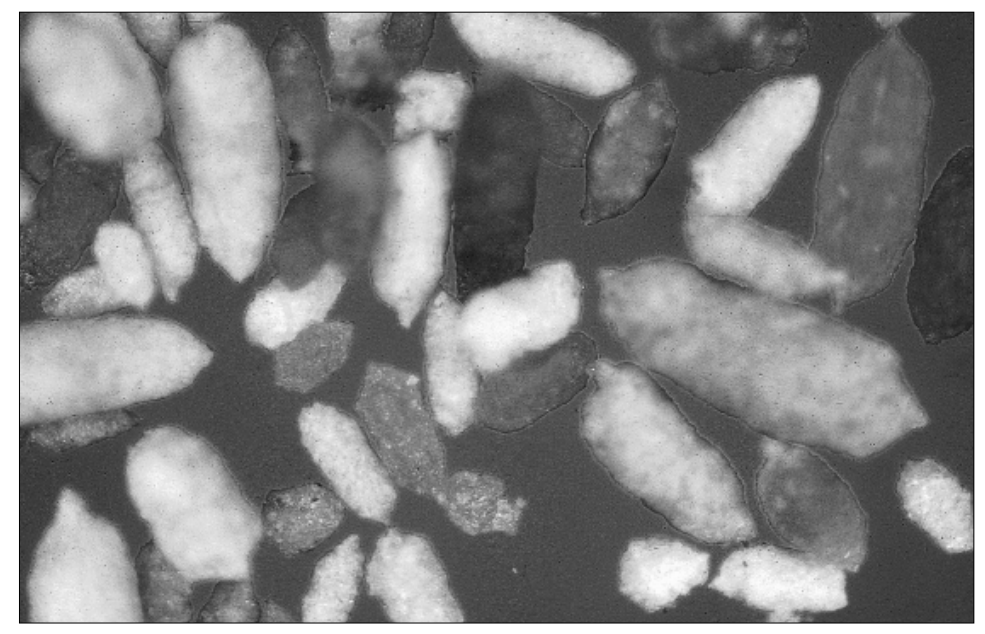

\section{Familia Cerambicidae}

- Hylotrupes bajulus (Linnaeus), "carcoma grande" o "capricornio doméstico"15,19,22. Xilófago y relativamente abundante, sobre todo localmente. La larva ataca preferentemente vigas y techumbres de madera de coníferas no muy viejas (necesita cierta humedad), haciendo galerías de diámetro elíptico mayor de $5 \mathrm{~mm}$, con grandes orificios de salida. Es blanquecina, de unos 3 a $3^{\prime} 5 \mathrm{~cm}$ de longitud. Los excrementos son típicamente de sección rectangular. El adulto es oscuro, con una mancha más clara aproximadamente en el centro de cada uno de los élitros; el macho mide I' 5 a I' $8 \mathrm{~cm}$, mientras que la hembra es mayor (unos $3 \mathrm{~cm}$ ). Sus ataques pueden ser importantes en edificaciones no cuidadas.

Algunas otras especies silvestres de esta familia de xilófagos pueden aparecer muy esporádicamente sobre objetos de madera ${ }^{15,19,22}$. Entre ellas pueden destacarse Hoplocerambyx spinicornis Newman, Clytus arietis (Linnaeus) y Ergates faber (Linnaeus).

\section{Familia Curculionidae ${ }^{19}$}

- Varias especies pueden causar daños en la madera en forma de galerías, pero son sumamente escasas en condiciones no silvestres. Entre ellas se pueden 
destacar Pentarthrum huttoni (Wollanston), Euophryum confine Brounier (importado de Nueva Zelanda) y varias especies de Rhyncolus Germar.

\section{Familia Scolytidae}

- Estos barrenadores silvestres muy raramente se encuentran asociados a objetos de madera elaborados por la mano humana. En alguna ocasión pueden aparecer como barrenadores relativamente superficiales las larvas de Trypodendron (=Xiloterus) lineatum (Olivier) ${ }^{19}$, Anisandrus dispar (Fabricius) ${ }^{19} \mathrm{o}$ especies del género $1 p s^{22}$. En la naturaleza viven bajo la corteza de árboles. El cuerpo de los adultos es rectangular, pardo oscuro, y se distingue con facilidad; las antenas son claviformes.

\section{Familia Platypodidae}

- Platypus cylindricus Fabricius ${ }^{15,19}$ y Xyleborus saxeseni (Fabricius) ${ }^{15,19}$ son dos especies xilófagas y silvestres que raramente aparecen sobre madera procesada. Los adultos tienen el cuerpo alargado, con forma rectangular, con muescas en los lados del tórax. Su biología es análoga a la de los escolítidos.

\section{Orden Lepidoptera}

Familia Tineidae

- Tinea pellionella Linnaeus, "polilla de la ropa"15,23,26. Existen otras 7 especies que forman un conjunto muy homogéneo de especies casi indistinguibles. Parece que no existen diferencias biológicas apreciables entre todas ellas, y los daños que producen deben ser análogos. Las larvas son queratófagas (se alimentan de pelo, pieles, cuero, etc.). El adulto es pardo con tres motas oscuras en cada ala anterior (envergadura: 7 a $9 \mathrm{~mm}$ ). La larva es blancuzca, con la cápsula cefálica parda (7 a $8 \mathrm{~mm}$ ). Se cobija en un tubo de seda mientras come. Huevo: 4 a 7 días; larva: 4 I a 56 días; pupa: 9 a 20 días; el adulto vive de 4 a 7 días. Es una especie cosmopolita y, en ocasiones, abundante.

- Tineola bisselliella (Hummel), "polilla de la ropa"15,23,26. Larvas también queratófagas. El adulto es amarillo dorado (alas de color uniforme), con mechones de pelo de color bronce en la cabeza (envergadura: 8 a $10 \mathrm{~mm}$ ). La larva es blancuzca ( 8 a $10 \mathrm{~mm}$ ). Como en la especie anterior, los daños se reconocen tanto por los orificios sobre el tejido como por los restos de pelo o fibra que caen. Huevo: 4 a 10 días; larva: 30 a 35 días (si no hay diapausa); pupa: 8 a 28 días; el adulto vive de 4 a 7 días. El ciclo puede durar hasta 4 años, si las condiciones ambientales son adversas. Especie cosmopolita; puede ser abundante.

\section{Orden Hymenoptera \\ Familia Siricidae \\ Familia Formicidae \\ Familia Sphecidae \\ Familia Vespidae \\ Familia Anthophoridae \\ Familia Andrenidae \\ Familia Halictidae \\ Familia Apidae}

- Todas estas familias contienen especies asociadas con madera en la naturaleza, que utilizan como refugio o para la reproducción. Es raro encontrarlas en la madera utlilizada en la industria artística, si bien las hormigas Camponotus herculeanus (Linnaeus) y C. ligniperda (Latreille) (Formicidae) pueden construir sus nidos en la parte baja de vigas y llegar a vaciarlas, y el "abejorro violeta de la madera" Xylocopa violacea (Linnaeus) (Apidae) puede hacer lo propio en partes altas de vigas y postes. Además, como se ha señalado, algunas especies de las mencionadas familias (excepto sirícidos y xilocópidos) pueden resultar dañinas en muros, paredes o esculturas de naturaleza mineral, al acumular sobre ellos sus nidos de barro o utilizar grietas para la nidificación.

Las condiciones ambientales influyen de manera importante sobre determinados atributos del ciclo vital de los insectos 16,27,28. En especial, pueden modificar I) la duración de determinadas fases del ciclo vital, y consecuentemente en ciertos casos el número de generaciones, y 2) la relación entre las tasas de natalidad y mortalidad, lo que puede dar lugar a oscilaciones poblacionales más o menos fuertes. Estas oscilaciones poblacionales son especialmente marcadas en los insectos ${ }^{28,29}$. Por ello, los datos sobre duración de las fases del ciclo vital y longevidad que se han dado son sólo aproximadas. Los incrementos poblacionales bruscos debidos a condiciones ambientales favorables pueden tener serias consecuencias en la conservación de los materiales atacados, por lo que es conveniente llevar a cabo seguimientos periódicos de la dinámica poblacional de las especies más dañinas.

\section{Análisis del deterioro causado por insectos y su diagnóstico}

Como se ha visto, el grupo de mayor importancia en cuanto a daños sobre materiales históricos y artísticos es el de los coleópteros, seguidos de isópteros y lepidópteros. Otro hecho a destacar es que muchas de las especies que nos interesan son de tamaño pequeño o muy pequeño, lo que va a condicionar los métodos de identificación.

A grandes rasgos, pueden reconocerse seis pasos en el estudio y diagnóstico de los insectos y del daño causado:

I. Recogida de muestras sobre el material afectado: a ser posible, debe recogerse tanto el material dañado como partes o restos de los insectos atacantes.

2. Identificación del causante del daño: debe intentarse una determinación a nivel de especie, lo que en general debe ser factible al no ser muchas las especies que nos podemos encontrar. En casos concretos de especies muy parecidas a simple vista, puede ser necesario recurrir a examinar las armaduras genitales. Para ello es suficiente un instrumental sencillo: lupa binocular, pinzas y agujas enmangadas, unos pocillos y potasa. El proceso es explicado en detalle en diversas publicaciones30,31,32. 
3. Reconstrucción del ciclo biológico: generalmente se realiza en función de datos bibliográficos, a los que se añaden observaciones previas. Como se ha señalado, el conocimiento de la dinámica poblacional es fundamental.

4. Reconstrucción del ambiente a que estuvo sometido el material: en general aporta pistas muy útiles para, valorando cómo fueron las condiciones en que el daño fue producido, proponer medios efectivos para la desinsectación.

5. Valoración del ataque: se realiza en función de la extensión del daño producido sobre el material atacado, y es necesario para establecer la intensidad del tratamiento desinsectante a seguir.

6. En su caso, recomendación sobre tratamiento desinsectante: si se trata de insectos que aún perdu- ran sobre el material, es necesario intentar erradicarlos por alguno de los métodos conocidos. Bletchly ${ }^{19}$ y Valentín 24 enumeran los más conocidos y proponen alguno nuevo. Básicamente, existen tres métodos de desinsectación:

a. por fumigación con biocidas líquidos (como bromuro de metilo) o gaseosos (humos de - BHC, DDT, dieldrina, nitrógeno);

b. por fumigación con gases inertes (como argón);

c. por tratamientos de choque con frío o calor intensos.

No debe olvidarse que a menudo hay asociación del insecto con hongos o bacterias, los cuales pueden ser tan dañinos o más. En estos casos es necesario también un estudio micológico o bacteriológico.
I. SAMEÑO PUERTO, M.; GARCÍA ROWE, J. (199). Biodeterioro. Alteración biológica de monumentos y obras de arte. Boletín del Instituto Andaluz del Patrimonio Histórico, 10, 26-27.

2. BOLÍVAR GALIANO, F. C. (199 ). Los agentes de biodeterioro del patrimonio pictórico, textil y gráfico. Boletín del Instituto Andaluz del Patrimonio Histórico, 12, 50-51.

3. SOUTHWOOD, T. R. E. (1978). The components of diversity. The diversity of insect faunas (ed. L. A. Mound \& N. Waloff), pp. 19-40. Blackwell Scientific Publications, London.

4. RICHARDS, O. W.; DAVIES, R. G. (1960). Imms' general textbook of Entomology (IOth edition). Chapman \& Hall, London.

5. PYLE, R. M.; BENTZIEN, M.; OPLER, P. (198I). Insect conservation. Annual Review of Entomology, 26, 233-258.

6. GROOMBRIDGE, B. (ed.) (1992). Global biodiversity. Status of the Earth's living resources: a report compiled by the World Conservation Monitoring Centre. Chapman \& Hall, London.

7. WILSON, E. O. (1988). The current state of biological diversity. Biodiversity (ed. E. O. Wilson), pp. 3- I8. National Academy Press, Washington.

8. EHRLICH, P. R.; WILSON, E. O. ( $99 \mid$ |). Biodiversity studies: science and policy. Science, 253, 758-762.

9. NEW, T. R. (1984). Insect conservation - an Australian perspective. Junk Publishers, Dordrecht.

10. MAY, R. M. (1990). How many species?. Philosophical Transactions of the Royal Society of London B, 330, 293-304.

II. Thomas, C. (1990). Fewer species. Nature, 347, 237.

12. GASTON, K. J. \& HUDSON, E. (1994). Regional patterns of diversity and estimates of global insect species richness. Biodiversity and Conservation, 3, 493-500.
13. MORILLO FERNÁNDEZ, C.; COMPTE SART, A. (1995). La diversidad entomológica ibérica: criterios de conservación. Avances en Entomología Ibérica (ed. Comité Editorial), pp. 65- 75. Asociación española de Entomología, Madrid.

14. YELA, J. L. (en evaluación). Conservation of insect diversity in Spain: from the shady past to the challenging future. Biological Conservation

I5. CHINERY, M. (1977). Guía de campo de los insectos de España y de Europa. Omega, Barcelona.

16. GULLAN, P. (1994). The insects: an outline of Entomology. Chapman \& Hall, London.

17. ELTON, C. S. (1958). The ecology of invasions by animal and plants. Methuen, London.

18. LODGE, D. M. (1993). Biological invasions: lessons for ecology. Trends in Ecology and Evolution, 8, 133- 137.

19. BLETCHLY, J. D. (1967). Insect and marine borer damage to timber and woodwork. Recognition, prevention and erradication. Her Majesty's Stationery Office, London.

20. PINNIGER, D. (1990). Insect pests in museums. Archetype Publications, Denbigh.

21. ZYCHERMAN, L. A.; SCHROCK, J. R. (ed.) (1988). A guide to museum pest control. Foundation of the American Institute for Conservation of Historic and Artistic Works and Association of Systematics Collections, Washington.

22. BERNIS MATEU, J. (1974). Principales insectos xilófagos de la Península. Reconocimiento y prevención. De re restauratoria, vol. 2. IV y $\vee$ cursos de conservación y restauración de monumentos y ambientes. Universidad Poliltécnica de Barcelona, Barcelona.

23. KINGSOLVER, J. M. (1988). Illustrated guide to common insect pests in museums. A guide to museum pest control (ed. L. A. 
$\leftarrow$

Ш
Zycherman \& J. R. Schrock), pp. 53-8I. Foundation of the American Institute for Conservation of Historic and Artistic Works and Association of Systematics Collections, Washington.

24. VALENTÍN, N. (1993). Comparative analysis of insect control by nitrogen, argon and carbon dioxide in museum, archive and herbarium collections. International Biodeterioration \& Biodegradation, 32, 263-278.

25. ESPAÑOL COLL, F. (1992). Coleoptera Anobiidae. Fauna Ibérica, vol. 2. Museo Nacional de Ciencias Naturales, CSIC, Madrid.

26. SCOBLE, M. J. (1992). The Lepidoptera. Form, function and diversity. Oxford University Press, Oxford.

27. Stearns, S. C. (1992). The evolution of life histories. Oxford University Press, Oxford.

28. VARLEY, C. G.; GRADWELL, G. R.; HASSELL, M. P. (1973). Insect population ecology - an analytical approach. University of California Press, Berkeley.
29. THOMAS, C. D. (1990). What do real population dynamics tell us about minimum viable population sizes? Conservation Biology, 4, 324-327.

30. BERIO, E. (1985). Noctuidae, I. Generalità. Hadeninae. CucuIllinae. Fauna d'Italia, vol. 22 (Lepidoptera). Calderini, Bologna.

31. LAFONTAINE, J. D.; MIIKOLA, K. (1987). Las-och-nyckel systemen i de inre genitalierna av Noctuidae (Lepidoptera) som taxonomiska kännetecken. Entomologiske Meddelelser, 55, 161 - 167.

32. YELA, J. L. (1992). Los Noctuidos (Lepidoptera) de la Alcarria (España Central) y su relación con las principales formaciones vegetales de porte arbóreo. Ministerio de Agricultura, Pesca y Alimentación, Madrid. 